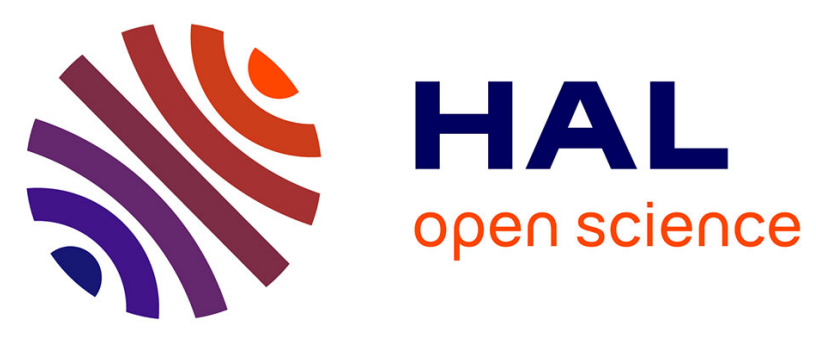

\title{
Phenotypic expansion of CACNA1C-associated disorders to include isolated neurological manifestations
}

Lance Rodan, Rebecca Spillmann, Harley Kurata, Shawn Lamothe, Jasmine

Maghera, Rami Abou Jamra, Anna Alkelai, Stylianos Antonarakis, Isis

Atallah, Omer Bar-Yosef, et al.

\section{To cite this version:}

Lance Rodan, Rebecca Spillmann, Harley Kurata, Shawn Lamothe, Jasmine Maghera, et al.. Phenotypic expansion of CACNA1C-associated disorders to include isolated neurological manifestations. Genetics in Medicine, 2021, 23 (10), pp.1922-1932. 10.1038/s41436-021-01232-8 . hal-03519600

\section{HAL Id: hal-03519600 \\ https://hal-univ-rennes1.archives-ouvertes.fr/hal-03519600}

Submitted on 12 Jan 2022

HAL is a multi-disciplinary open access archive for the deposit and dissemination of scientific research documents, whether they are published or not. The documents may come from teaching and research institutions in France or abroad, or from public or private research centers.
L'archive ouverte pluridisciplinaire HAL, est destinée au dépôt et à la diffusion de documents scientifiques de niveau recherche, publiés ou non, émanant des établissements d'enseignement et de recherche français ou étrangers, des laboratoires publics ou privés. 
Title: Phenotypic expansion of $C A C N A 1 C$-associated disorders to include isolated neurological manifestations

Lance H. Rodan MD, ${ }^{1,2}$ Rebecca C. Spillmann MS CGC, ${ }^{3}$ Harley T. Kurata PhD, ${ }^{4}$ Shawn M. Lamothe PhD, ${ }^{4}$ Jasmine Maghera BS, ${ }^{4}$ Rami Abou Jamra MD, ${ }^{5}$ Anna Alkelai PhD, ${ }^{6}$ Stylianos E. Antonarakis MD, DSc, ${ }^{7}$ Isis Atallah MD, ${ }^{8}$ Omer Bar-Yosef MD, PhD, ${ }^{9,10}$ Frédéric Bilan PhD, ${ }^{11}$ Kathrine Bjorgo MD, ${ }^{12}$ Xavier Blanc PhD, ${ }^{7}$ Patrick Van Bogaert MD, PhD, ${ }^{13}$ Yoav Bolkier MD, ${ }^{10,14}$ Lindsay C. Burrage MD, PhD, ${ }^{15}$ Björn U. Christ MA, ${ }^{16}$ Jorge L. Granadillo MD, ${ }^{17}$ Patricia Dickson MD, ${ }^{17}$ Kirsten A. Donald MBChB, PhD, ${ }^{16}$ Christèle Dubourg PhD, ${ }^{18,19}$ Aviva Eliyahu MD, ${ }^{10,20,21}$ Lisa Emrick MD, ${ }^{15}$ Kendra Engleman MS, CGC, ${ }^{22}$ Michaela Veronika Gonfiantini MD, ${ }^{23}$ Jean-Marc Good MD, PhD, ${ }^{24}$ Judith Kalser MD, ${ }^{25}$ Chiara Kloeckner CM, ${ }^{5}$ Guus Lachmeijer MD, PhD, ${ }^{26}$ Marina Macchiaiolo MD, ${ }^{23}$ Francesco Nicita MD, ${ }^{27}$ Sylvie Odent MD, ${ }^{28}$ Emily O'Heir BS, ${ }^{1,29}$ Xilma Ortiz-Gonzalez MD, PhD, ${ }^{30}$ Marta Pacio-Miguez MS, ${ }^{31}$ María Palomares-Bralo MSc, PhD, ${ }^{31}$ Loren Pena MD, PhD, ${ }^{32,33}$ Konrad Platzer MD, ${ }^{5}$ Mathieu Quinodoz PhD, ${ }^{34,35}$ Emmanuelle Ranza MD, ${ }^{7}$ Jill A. Rosenfeld MS, CGC, ${ }^{15}$ Eliane Roulet-Perez MD, ${ }^{25}$ Avni Santani PhD, ${ }^{36,37}$ Fernando SantosSimarro MD, ${ }^{31}$ Ben Pode-Shakked MD, ${ }^{10,38}$ Cara Skraban MD, ${ }^{37,39}$ Rachel Slaugh MS, CGC, ${ }^{17}$ Andrea Superti-Furga MD, ${ }^{24}$ Isabelle Thiffault PhD, ${ }^{22}$ Richard H. van Jaabrsveld PhD, ${ }^{26}$ Marie Vincent MD, ${ }^{40}$ HongGang Wang PhD, ${ }^{41}$ Pia Zacher MD, ${ }^{42}$ Undiagnosed Diseases Network*, Eric Rush MD, ${ }^{43,44,45}$ Geoffrey Pitt $\mathrm{MD}, \mathrm{PhD},{ }^{41}$ Ping Yee Billie Au MD, PhD, ${ }^{46}$ Vandana Shashi MBBS, MD, ${ }^{3}$ "

1. Division of Genetics and Genomics, Department of Pediatrics, Boston Children's Hospital, Boston, MA, 02115, USA

2. Department of Neurology, Boston Children's Hospital, Boston, MA, 02115, USA

3. Division of Medical Genetics, Department of Pediatrics, Duke Health, Durham, NC 27710, USA

4. Department of Pharmacology, Alberta Diabetes Institute, University of Alberta, Edmonton, AB, Canada

5. Institute of Human Genetics, University of Leipzig Medical Center, Leipzig, Germany.

6. Institute for Genomic Medicine, Columbia University Medical Center, New York, USA

7. Medigenome, Swiss Institute of Genomic Medicine, 1207 Geneva, Switzerland

8. Division of Genetic Medicine, Lausanne University Hospital, 1011 Lausanne, Switzerland

9. Pediatric Neurology Unit, Edmond and Lily Safra Children's Hospital, Sheba Medical Center, Tel-Hahsomer, 52621, Israel

10. Sackler Faculty of Medicine, Tel-Aviv University, Tel-Aviv, 6997801, Israel

11. CHU de Poitiers; Service de Génétique; EA3808 NEUVACOD

12. Department of Medical Genetics, Oslo University Hospital, Oslo, Norway

13. CHU d'Angers, Service de Pédiatrie; EA3808 NEUVACOD

14. Pediatric Cardiology Unit, Edmond and Lily Safra Children's Hospital, Sheba Medical Center, Tel-Hahsomer, 52621, Israel

15. Department of Molecular \& Human Genetics, Baylor College of Medicine, Houston, TX, USA Division of Genetics and Genomic Medicine, Department of Pediatrics, Washington University School of Medicine in St. Louis, St. Louis, MO., USA

Service de Génétique Moléculaire et Génomique, CHU, Rennes, F-35033, France

University of Rennes, CNRS, IGDR, UMR 6290, Rennes, F-35000, France

The Danek Gertner Insitute of Human Genetics, Sheba Medical Center, Tel-Hahsomer, 52621, Israel

Edmond and Lily Safra Children's Hospital, Sheba Medical Center, Tel-Hahsomer, 52621, Israel;

Center for Pediatric Genomic Medicine, Children's Mercy Hospital, Kansas City, MO, USA

Rare Diseases and Medical Genetic Unit, IRCCS Bambino Gesù Children's Hospital, Rome, Italy

Division of Genetic Medicine, Lausanne University Hospital, 1011 Lausanne, Switzerland

Pediatric Neurology, Lausanne University Hospital, 1011 Lausanne, Switzerland

Department of Genetics, University Medical Center Utrecht, Utrecht, The Netherlands 
Unit of Neuromuscular and Neurodegenerative Diseases, Department of Neurosciences and Neurorehabilitation, IRCCS Bambino Gesù Children's Hospital, Rome, Italy Service de Génétique Clinique, Centre de référence "Maladies Rares" Anomalies du développement CLAD-Ouest, Hôpital SUD Center for Mendelian Genomics and Program in Medical and Population Genetics, Broad Institute of MIT and Harvard, Cambridge, MA, USA Division of Neurology, Children's Hospital of Philadelphia, Philadelphia, PA, USA

31. Instituto de Genética Médica y Molecular (INGEMM), Hospital Universitario La Paz, IdiPAZ, CIBERER, ISCIII, Madrid, 28046, Spain

32. Cincinnati Children's Hospital and Medical Center Cincinnati OH 45229, USA

33. University of Cincinnati College of Medicine Cincinnati OH 45229, USA

34. Institute of Molecular and Clinical Ophthalmology Basel (IOB), Basel, Switzerland

35. Department of Ophthalmology, University of Basel, Switzerland

Division of Genomic Diagnostics, Children's Hospital of Philadelphia, Philadelphia, PA

Department of Pediatrics, Perelman School of Medicine at the University of Pennsylvania, Philadelphia, PA

Institute of Rare Diseases, Edmond and Lily Safra Children's Hospital, Sheba Medical Center, Tel-Hahsomer, 52621, Israel

39. Division of Human Genetics, Children's Hospital of Philadelphia, Philadelphia, PA, USA Service de Génétique Médicale, CHU Nantes, France; Inserm, CNRS, Univ Nantes, I'institut du thorax, Nantes, France; Cardiovascular Research Institute, Weill Cornell Medicine, New York, NY 10022, USA

The Saxon Epilepsy Center Kleinwachau, Radeberg, Germany

The Children's Mercy Hospital, Kansas City, MO, USA

Department of Pediatrics University of Missouri - Kansas City, Kansas City, MO, USA

Department of Internal Medicine, University of Kansas Medical Center, Kansas City, MO, USA

Alberta Children's Hospital Research Institute, Department of Genetics, Cumming School of Medicine, University of Calgary, Calgary, AB, Canada

*a full list of members appears in the Supplementary information

\section{"Corresponding Author:}

Vandana Shashi, MBBS, MD

Professor of Pediatrics

Division of Medical Genetics

Department of Pediatrics

Duke University School of Medicine

Durham NC 27710

Email: vandana.shashi@duke.edu

Tel: 919-681-2616 


\begin{abstract}
:
Purpose: CACNA1C encodes the alpha-1-subunit of a voltage-dependent L-type calcium channel expressed in human heart and brain. Heterozygous variants in CACNA1C have previously been reported in association with Timothy syndrome and Long QT syndrome. Several case reports have suggested that CACNA1C variation may also be associated with a primarily neurological phenotype.
\end{abstract}

Methods: We describe 25 individuals from 22 families with heterozygous variants in CACNA1C, who present with predominantly neurological manifestations.

Results: Fourteen individuals have de novo, non-truncating variants and present variably with developmental delays, intellectual disability, autism, hypotonia, ataxia, and epilepsy. Functional studies of a subgroup of missense variants via patch-clamp experiments demonstrated differential effects on channel function in vitro, including loss-of-function (p.Leu1408Val), neutral effect (p.Leu614Arg), and gain-of-function (p.Leu657Phe, p.Leu614Pro). The remaining 11 individuals from eight families have truncating variants in CACNA1C. The majority of these individuals have expressive language deficits, and half have autism.

Conclusion: We expand the phenotype associated with CACNA1C variants to include neurodevelopmental abnormalities and epilepsy, in the absence of classic features of Timothy syndrome or Long QT syndrome. 


\section{Introduction:}

CACNA1C (MIM:114205) encodes the alpha-1 subunit of a voltage-dependent L-type calcium channel that is broadly expressed and best studied in human heart, brain, smooth muscle, and endocrine tissue ${ }^{1}$. Pathogenic variants in CACNA1C are associated with various cardiac rhythm disorders. Specific heterozygous gain-of-function variants are associated with Timothy syndrome (MIM:601005), a multisystem disorder characterized by long QT interval, structural cardiac defects, dysmorphic facial features, syndactyly, intellectual disability, autism, hypotonia, and, less commonly, epilepsy ${ }^{1}$. Heterozygous gain-of-function variants have also been reported in association with non-syndromic Long QT syndrome ${ }^{2}$. Loss-of-function variants in CACNA1C were previously implicated as a cause of Brugada syndrome (MIM:611875), but this association has not been firmly established ${ }^{3}$.

In addition to the role of CACNA1C in cardiac rhythm disorders, this gene has also been implicated in diverse neurological phenotypes. Polymorphisms in CACNA1C are associated with increased risk of schizophrenia, major depressive disorder, bipolar disorder, and autism ${ }^{4}$. One individual presenting with neonatal epileptic encephalopathy has been previously reported with a de novo, rare missense variant in CACNA1C; functional studies were not performed ${ }^{5}$. Individuals with de novo variants in CACNA1C have been detected in large-scale sequencing studies for neurodevelopmental disorders, including two individuals with missense variants and an individual with a truncating variant ${ }^{6.7}$. In addition, two individuals with intragenic deletions in CACNA1C in association with neurodevelopmental and behavioral abnormalities have been previously reported ${ }^{8}$. There is also a report of a de novo, intragenic duplication within CACNA1C in a child with learning disabilities $^{9}$. There have also been numerous reports of individuals with neurodevelopmental phenotypes associated with deletions at $12 p$, both interstitial and terminal, disrupting $C A C N A 1 C^{10}$. This has led to speculation that haploinsufficiency of this gene may 
largely account for the neurodevelopmental phenotype of $12 \mathrm{p} 13.33$ interstitial deletion syndrome ${ }^{8}$. Finally, one large Chinese kindred was reported with a heterozygous intronic variant in CACNA1C segregating with an adult-onset autosomal dominant cerebellar ataxia phenotype ${ }^{11}$.

Here we describe 25 new individuals from 22 families with novel variants in the CACNA1C gene presenting with a predominantly neurological phenotype, variably including developmental delay, intellectual disability, autism, hypotonia, epilepsy, and ataxia, in the absence of significant cardiac manifestations or additional features of Timothy syndrome. Broad phenotypic differences were evident between those with non-truncating and truncating variants. We functionally characterize a subgroup of these variants with patch clamping. 


\section{Patients and Methods:}

\section{Ascertainment of cases}

Cases were ascertained from GeneMatcher through the Matchmaker Exchange Network between July 2018 and March $2020^{12,13}$. In addition, 2 cases were ascertained through the ClinVar database. CACNA1C variants in index cases were detected on exome sequencing or intellectual disability gene panel. Additional genetic findings for individual patients are summarized in the supplement. Signed consent was obtained from parents/legal guardians for publication of photographs, in accordance with the institutional review boards/ethics committees at each institution.

Selection of variants for functional studies:

Whole-cell patch clamp analysis to assess functionality of the Cav1.2 calcium channels was conducted for a small number of missense variants: (p.Leu614Pro), (p.Leu614Arg), (p.Leu657Phe) and (p.Leu1408Val). These variants were specifically selected because they are located near channel regions where there appeared to be a clustering of variants in the cohort, and are likely of functional importance. For our selection of variants to functionally characterize, we also considered intolerance to variation of the residue, and whether variants at homologous residues in related channels have been reported as pathogenic.

Whole-cell patch clamp electrophysiology of p.Leu614Arg variant

Human CACNA1C cDNA (Accession no. NM_000719) was mutagenized to generate p.Leu614ARg using site-directed mutagenesis (Agilent), following the manufacturer's instructions using the following primers: 5' CAAGATCATGTCCCCAAGAGGCATCTCCGTGCTCAG 3' (forward) and 5' CTGAGCACGGAGATGCCTCTTGGGGACATGATCTTG 3' (reverse). The underlined and bolded nucleotides indicate the variant. Wild type or p.L614R CACNA1C (3 $\mu \mathrm{g})$ along with CACNB2 (1.5 $\mu \mathrm{g})$ and CACNA2D 
$(1.5 \mu \mathrm{g})$ and EGFP $(0.3 \mu \mathrm{g})$ were transfected into HEK293 cells using Lipofectamine 2000 (ThermoFisher Scientific, MA). The HEK293 cells were grown in Dulbecco's modified Eagle's culture medium with 10\% fetal bovine serum in $60-\mathrm{mm}$ culture dishes in a $37^{\circ} \mathrm{C}$ incubator with $5 \% \mathrm{CO}_{2}$. Whole-cell voltage-gated calcium currents were measured as previously described ${ }^{14}$.

Whole-cell patch clamp electrophysiology and Western blot of p.Leu614Pro, p.Leu657Phe and p.Leu1408Val variants

Molecular Biology and Mutagenesis:

The mouse Cav1.2 (Cacna1c; clone \#26572), the rat Cavß3 (Cacnb3; clone\#26574) and the rat Cava281 (Cacna2d1; clone \#26575), as previously described ${ }^{15}$, were obtained from Addgene. The p.Leu614Pro, p.Leu657Phe, and p.Leu1408Val variants of Cav1.2 were generated by site-directed mutagenesis.

\section{Cell Culture:}

HEK293 cells were used for patch clamp and Western blot experiments. HEK cells were cultured and maintained using standard cell culture approaches as previously described ${ }^{16}$. Transfection was performed using jetPRIME (Polypus) according to the manufacturer's instructions. Calcium currents were recorded 72 hours following transfection. Western blots were performed 72 hours after transfection.

Whole-cell patch clamp electrophysiology:

Patch clamp experiments were performed as previously described ${ }^{16}$. Solutions used for Whole cell patch clamp recordings were: Bath solution (in $\mathrm{mM}$ ): 135 choline- $\mathrm{Cl}, 1 \mathrm{MgCl}_{2}, 2 \mathrm{CaCl}_{2}$, and $10 \mathrm{HEPES}$, adjusted to $\mathrm{pH} 7.4$ with $\mathrm{CsOH}$; Pipette solution: $135 \mathrm{CsCl}, 4 \mathrm{MgATP}, 1 \mathrm{EGTA}, 1$ EDTA, and 10 HEPES, adjusted to pH 
7.4 with $\mathrm{CsOH}$. Experiments were conducted at room temperature $\left(22 \pm 1^{\circ} \mathrm{C}\right)$. Currents were adjusted with $\mathrm{P} / 4$ leak subtraction during data acquisition.

Western blot:

Cell lysates were collected in NP-40 lysis buffer (1\% NP-40, $150 \mathrm{mM} \mathrm{NaCl}, 50 \mathrm{mM}$ Tris-HCl)

supplemented with $1 \%$ protease inhibitor, 72 hours after transfection. Western blots were performed as

previously described ${ }^{16}$. Cav1.2 was detected using a mouse monoclonal Cav1.2 antibody (1:1000

dilution, clone \#L57/46; NeuroMab) and HRP-conjugated goat anti-mouse antibody (1:20,000 dilution, SH023; Applied Biological Materials).

\section{Results:}

Demographics, molecular data, and clinical characteristics for our cohort are summarized in tables 1 and 2 (More detailed clinical information for each individual, including variants of uncertain significance identified in additional genes, is provided in the Supplementary Data). Thirteen individuals are male, and 12 are female. Age at most recent follow-up ranges from 10 months to 40 years (median age 6.8 years).

Thirteen unrelated individuals have missense variants in CACNA1C, one individual has an in-frame deletion, and 11 individuals from 8 families have predicted truncating variants, including one canonical splice variant. All the non-truncating variants and all but three of the truncating variants occurred de novo. The three truncating variants that were inherited segregated with neurodevelopmental abnormalities in the families. None of the variants in our cohort are found in public databases, including the Broad Genome Aggregation Database (gnomAD)

(https://www.biorxiv.org/content/10.1101/531210v4), 1000 genomes $^{17}$, or the Exome Variant Server (Exome Variant Server, NHLBI GO Exome Sequencing Project (ESP), Seattle, WA (URL:

http://evs.gs.washington.edu/EVS/L. All missense variants occur at highly conserved positions and are 
predicted by in silico models to be damaging (Mutation Taster, Poly-Phen2, SIFT). CADD scores are listed in table 1 . One truncating variant we describe occurs in exon $45 / 45$, potentially escaping nonsensemediated decay. All other reported truncating variants are predicted to be subject to nonsensemediated decay.

Non-truncating variants: For individuals with missense variants and the in-frame deletion (i.e. nontruncating variants), prenatal history was remarkable for reduced fetal movement $(n=3 / 14)$, bilateral clubfoot detected on prenatal ultrasound $(n=2 / 14)$, and oligohydramnios $(n=2 / 14)$. All growth parameters at birth were normal except one individual with IUGR. Two individuals had neonatal feeding difficulties.

All 14 individuals with non-truncating variants have a history of developmental delays or intellectual disability. Two individuals, after early delays, currently have a learning disability. Nine individuals are non-verbal at most recent follow-up, and six are non-ambulatory (age at last evaluation ranging from 2 years to 24 years). This does not include one individual that is still an infant (10 months at last evaluation), who is manifesting severe global developmental delays and is unable to babble, roll, or sit. One individual has been formally diagnosed with autism, and six additional individuals have autistic features, including stereotypies and abnormal socialization. The overall developmental trajectory in our cohort is consistent with a static neurodevelopmental disorder. Regression was reported in one individual within the context of developing infantile spasms.

Twelve of 14 individuals in this group are hypotonic, and four are described as having abnormal balance and coordination (ataxia). One individual was diagnosed with bilateral vestibular areflexia.

Ten of 14 individuals in our cohort with non-truncating variants have epilepsy, with onset ranging from 2 months to 8 years. Clinical details are summarized in table 1. Both generalized and focal epilepsy disorders were reported. Fever sensitivity was reported in 3 individuals. Epilepsy was medically 
refractory in 4 individuals. On EEG, both generalized and focal epileptiform abnormalities were seen across the cohort, without consistent patterns. One individual was reported to have excessive diffuse fast (beta) activity. MRI brain was normal in all individuals that underwent imaging, with the exception of an incidentally detected arachnoid cyst in one individual and prominent cerebellar folia in another individual.

Eleven of the individuals with non-truncating variants had at least one ECG. One individual had mildly prolonged QTc on routine ECG at 7 years of age. Holter monitoring in this individual found significant QT prolongation, especially at higher heart rates (decreased repolarization reserve), and evidence of repolarization instability with macroscopic T wave alternans. Another individual had a possible ventricular conduction delay on routine ECG. Holter monitoring in this individual demonstrated only premature ventricular contractions. The other 9 individuals had normal ECGs. Nine individuals had echocardiograms; seven were entirely normal; one individual had trace aortic insufficiency, trivial tricuspid regurgitation, and trace pulmonary regurgitation; and one individual had a small interatrial communication in the upper part of the atrial septum with a left-right shunt.

Orthopedic abnormalities were common in individuals with non-truncating variants $(n=12 / 14)$. Two of the individuals had bilateral clubfoot and congenital finger contractures. Two additional individuals had persistently adducted thumbs. Additional orthopedic abnormalities include kyphosis or scoliosis ( $n=2 / 14)$; congenital hip dysplasia $(n=3 / 14)$; syndactyly ( $n=2 / 14)$; and joint hypermobility $(n=3 / 14)$.

Additional variable features in the individuals with non-truncating variants include leg spasticity $(n=1 / 14)$, tremor $(n=2 / 14)$, hyperopia $(n=4 / 14)$, strabismus $(n=4 / 14)$.

For the most part, growth parameters are normal in individuals with non-truncating variants. Two individuals are microcephalic, and the remainder are normocephalic. Three individuals have short stature $\left(<3^{\text {rd }} \%\right.$ ile for height), including the two with history of clubfoot. Minor facial dysmorphisms are 
seen in a number of individuals (see figure 1), but there are no consistent features and only two of the individuals have the syndactyly characteristic of Timothy syndrome.

Whole-cell patch clamp analysis was conducted to assess functionality of the Cav1.2 calcium channels in individuals with missense variants (p.Leu614Pro), (p.Leu614Arg), (p.Leu657Phe) and (p.Leu1408Val).

These variants were initially selected because they are located in or near regions where there appeared to be a clustering of variants in our cohort and also channel regions with likely functional importance. L614 is a recurrently affected residue, and located in close physical proximity to other variants (L601R and M611T) in the apex of the Domain II voltage sensor. L657F (Domain II, S5) is located in close proximity to V401M (Domain I, S6) in a neighboring domain, near the cytoplasmic gate. Lastly L1408V is nearly adjacent to V1411 (Domain IV, S5), also near the cytoplasmic gate. Review of the variants using MetaDome also indicates that the L657 and L1408 residues are located in regions highly intolerant to variation, and variants at homologous residues in related channels have been reported as pathogenic ${ }^{18}$. Missing from the functional characterization thus far are clusters of variants in S1 and outer pore of Domain I. Based on our initial characterization of 4 missense variants, as described below, we recognized that there were disparate effects and a more comprehensive study would be required as data from more patients and variants is collected. Cav1.2 (p.Leu1408Val) displays an overall reduction in current density (Figure 2) with unaltered activation kinetics compared WT Cav1.2. Missense variants (p.Leu614Pro and p.Leu657Phe) appear to transmit gain-of-function properties to the channel. Modest current increases were observed with the p.Leu614Pro variant, but were not statistically significant (Figure 2). A more pronounced, statistically significant enhancement of calcium current was observed with the p.Leu657Phe variant (Figure 2). The larger currents were also accompanied by shifts in the voltage-dependence of activation, in a hyperpolarizing direction for these variants. Western blot analysis was employed to identify whether the gain- or loss- of -function effects were a result of altered protein expression (Figure 2). Compared to WT Cav1.2, the p.Leu657Phe variant was associated with elevated 
proteins levels (Figure 2), providing explanation for the drastic increase in calcium current with this variant. Protein levels were similar to WT with the p.Leu614Pro and p.Leo1408Val variants. The p.Leu614Arg variant did not appear to confer any statistically significant change in current or properties of voltage-dependent gating (see Figure 2).

To account for the possibility that a variant may create a cryptic splice site, the Transcript-inferred Pathogenicity (TraP) score was reviewed for all missense variants (Supplementary Data). The TraP score utilizes an algorithm that can detect creations and disruptions of cryptic splice sites by a variant ${ }^{19}$. The TraP scores reported for each missense variant in the cohort fell between $0-0.359$, suggesting that none of the variants would be strongly predicted to affect splicing.

Truncating variants: For individuals with truncating variants, prenatal history was unremarkable, other than one individual with maternal history of gestational diabetes and one individual with maternal history of cholestasis of pregnancy. All growth parameters at birth were normal. The neonatal period was uncomplicated in most individuals, with the exception of perinatal respiratory difficulties in one individual and feeding difficulties in another individual.

In contrast to the individuals with non-truncating variants, most of the individuals with truncating variants in our cohort had essentially normal early motor development and achieved independent ambulation. Five of 11 individuals with truncating variants have been diagnosed with autism, and 3 of these individuals are considered non-verbal. An additional individual was previously diagnosed with pervasive developmental disorder not otherwise specified. Only $1 / 11$ of these individuals has a history of seizures, and this individual is currently seizure-free without treatment. Only three of the individuals in this group have hypotonia (tone is reported as unknown for $3 / 11$ ). Four individuals are described as having poor balance or coordination, and two individuals have a tremor. One individual with a de novo 
truncating variant is described as having paroxysmal dyskinesia, and another with a paternally inherited truncating variant had a paroxysmal movement disorder in infancy that subsequently resolved.

Only $5 / 11$ of individuals with truncating variants had an ECG, which was normal in all cases. One individual has undergone an echocardiogram that was normal. Seven of the individuals are reported to have minor dysmorphic features. Recurrent infections, including otitis media, were reported in 4/11 individuals; one of these individuals was diagnosed with hypogammaglobulinemia. One individual has a history of cryptorchidism.

\section{Discussion:}

We ascertained 25 individuals from 22 families with heterozygous variants in the CACNA1C gene presenting with a neurological phenotype variably associated with developmental delay, intellectual disability, autism, motor abnormalities, and epilepsy. While our sample size is limited, there were apparent phenotypic differences between individuals with non-truncating (missense variants, in-frame deletion) and truncating variants in our cohort.

Non-truncating variants in our cohort all occurred de novo. As a group, the individuals with nontruncating variants had more severe global developmental delay/intellectual disability and motor impairment compared to those with truncating variants. About half were non-verbal and nonambulatory at most recent follow-up. The majority had hypotonia. One of the individuals in this group was formally diagnosed with autism, although six additional had autistic behaviors.

Epilepsy was much more common in the group with non-truncating variants, present in more than twothirds of individuals. A spectrum of epilepsy syndromes and phenotypes were found, ranging from medically refractory infantile epileptic encephalopathy to later onset focal or generalized seizures with good response to anticonvulsants. Seizures were fever-sensitive in a number of individuals. There were 
no consistent EEG findings across the cohort. One individual was found to have excess fast activities similar to the previously reported infant with CACNA1C-related epileptic encephalopathy, but this is generally viewed as a non-specific finding and may be a medication effect ${ }^{5}$.

Two of the individuals in our cohort with non-truncating variants have a history of bilateral clubfoot and congenital finger contractures. Bilateral clubfoot and camptodactyly was also reported in the previously reported individual with neonatal epileptic encephalopathy associated with a de novo missense variant in $C A C N A 1 C^{5}$. This may represent a less common manifestation of the CACNA1C-related neurological disorder.

In contrast, three of the truncating variants in our cohort were familial (paternally inherited). These individuals as a group appeared to have more selective developmental abnormalities involving expressive language; 10/11 individuals in this group had delayed expressive language, whereas early motor development was essentially normal in all but one patient. Autism was more common in this group, present in 5/11 individuals. Finally, there appeared to be variable penetrance and expressivity of features amongst different family members with truncating variants.

Only one of the individuals in our cohort (P13; p.Val1411Leu) is known to have cardiac disease (prolonged QT), and none has physical features of Timothy syndrome, highlighting the novel, CNSpredominant clinical presentation of the reported individuals.

The CACNA1C channel subunit is broadly expressed in brain, heart, smooth muscle, endocrine tissue, and connective tissue, where it regulates cellular excitability, calcium signaling, and has downstream effects on gene expression ${ }^{20}$. In the central nervous system, CACNA1C shows the highest expression in the cerebral cortex, hippocampi, thalami, cerebellum, and suprachiasmatic nucleus ${ }^{5}$. It has also been implicated in the development of the serotonergic system ${ }^{21}$. These neuroanatomic substrates can account for the reported neurological phenotypes in our cohort. 
The CACNA1C channel consists of 4 homologous domains (DI-DIV), each comprised of 6 transmembrane segments, cytoplasmic segments, and transmembrane linker segments ${ }^{1,22}$. Variants reported in association with Timothy syndrome cluster in the C-terminal end of the $\mathrm{S} 6$ transmembrane segment of domain I or in the DIII-DIV loop, and cause a gain-of-function either by decreasing voltage-dependent inactivation or increasing "window" current, respectively" ${ }^{1,22}$. Similarly, non-syndromic Long QT syndrome has been associated with gain-of-function variants in the DI-DII loop and elsewhere ${ }^{23}$. The reported protein alterations in our cohort are spread throughout the protein, although there is a clustering of missense variants in one of the linker segments of DII (exon 13) and DIV (exon 35), suggesting the potential significance of these regions of the protein in the function of CACNA1C in the central nervous system (Figure 3).

CACNA1C functions as a component of a larger complex with accessory subunits, including auxiliary $\beta$ and $\alpha 2 \delta$ subunits ${ }^{20}$. There are tissue-specific differences in these accessory subunits between brain and heart that allow for modifications in channel function. In addition, CACNA1C undergoes extensive alternative splicing, with some transcripts undergoing additional RNA editing ${ }^{24,25}$. It has recently been suggested that there are 241 unique CACNA1C transcripts in the human brain, and that these may encode channels with altered function and different kinetics ${ }^{24}$. Further, different brain regions may themselves exhibit different CACNA1C splicing profiles ${ }^{24}$. These complexities in the interaction of CACNA1C with different accessory subunits, and plethora of CACNA1C isoforms in the central nervous system make interpretation of the effects of rare variants in this gene challenging.

To provide further insight into the molecular mechanism of disease in our cohort, we performed patch clamping on a subgroup of variants in our cohort. These studies demonstrated diverse effects on channel current associated with specific variants, including loss-of-function (p.Leu1408Val), neutral effect (p.Leu614Pro, p.Leu614Arg), and gain-of-function alterations (p.Leu657Phe). It is important to 
note that these functional studies were conducted only in the canonical transcript, and so it is possible that employing alternate transcripts could yield different results. Also, the patch clamp experiments of the p.Leu1408Val, p.Leu657Phe, and p.Leu614Pro variants yielding abnormal results were conducted using the CACNB3 accessory subunit, whereas the experiments for the p.Leu614Arg variant yielding normal results utilized CACNB2. The reason for this discrepancy is that the work evolved in multiple centers, as contributing clinical groups were simultaneously identifying CACNA1C variants and characterizing their effects with tools available to them. The landscape of potential combinations of beta subunits (each with multiple splice variants) and CACNA1C variants is broad, and it is uncertain yet which conditions are best to reveal relevant functional disruptions. The CACNB3 accessory subunit has a relatively higher expression in brain versus heart compared to CACNB2. The specific accessory subunits used for the patch clamp experiments could potentially affect the results and may also have implications regarding why the particular variants we report have predominant CNS manifestations in the relative absence of cardiac findings.

Overall, the missense variants tested thus far did not cause pronounced changes in the voltagedependence or kinetics of gating. Variants differed in terms of overall current density and protein expression. The gain-of-function effect of the Leu657Phe variant is most likely explained by an increase in protein expression, as both the current density and protein level increased by approximately 2 -fold. The Leu1408Val variant appears to have a clear effect on overall channel activity, as current density associated with this variant was significantly reduced to approximately $30 \%$ of control, but the protein expression was unchanged.

The finding that both CACNA1C gain of function and loss of function can result in a neurological phenotype is not unexpected, and there is a precedent for other CNS-expressed calcium channels to be dosage sensitive (eg. CACNA1A) ${ }^{26}$. Timothy syndrome is caused by CACNA1C gain of function, and 
frequently has a neurological phenotype, including intellectual disability, autism, hypotonia, and rarely epilepsy. Conversely, truncation/deletion of $C A C N A 1 C$ has previously been reported in association with developmental delay/intellectual disability, and it has been suggested that CACNA1C is haploinsufficient ${ }^{10}$. This is further supported by constraint analysis on the gnomAD dataset, demonstrating an observed/expected ratio of for predicted loss-of-function variants of 0.05 and probability of loss-of-function intolerance $(\mathrm{pLI})$ score of $1.0^{27}$. It is still not clear how loss-of-function variants in CACNA1C result in an epilepsy syndrome, since reduced channel activity in excitatory pyramidal neurons would theoretically be protective against seizures. It is possible that the CACNA1C channel is also expressed in GABAergic inhibitory interneurons, analogous to the mechanism seen with loss-of-function SCN1A pathogenic variants that result in Dravet syndrome ${ }^{28}$.

In individuals with missense variants in our cohort associated with a loss-of-function on patch clamp studies, it remains unknown whether the basis is haploinsufficiency or a dominant negative effect, potentially by encoding non-functioning channels that compete with wild-type for accessory subunits, or preventing the correct folding of wild type protein. The more severe neurodevelopmental and epilepsy phenotype in patients with missense, predicted loss-of-function variants compared to those with whole gene/exonic deletions would better support a dominant-negative effect.

In terms of the variant with an apparent neutral effect on patch clamp experiments, there are a number of possible explanations. As previously stated, it is possible that employing alternate transcripts or accessory subunits for patch clamp studies for these variants could have yielded different results. Splicevariant dependent gating changes have previously been demonstrated in another calcium channel subunit gene, $C A C N A 1 A^{29}$. Another possibility is differential effects of a variant in vivo due to proteinprotein interactions. Finally, one could hypothesize that specific CACNA1C transcripts serve noncanonical roles in the central nervous system that were not captured on our patch clamp studies. 
Further exploration of these variants in more complex systems such as iPSC-derived neurons, and a more comprehensive study of additional variants, may reveal trends in underlying functional outcomes.

Our study was underpowered to correlate phenotypic differences in patients with missense variants between those with predicted gain or loss-of-function on patch clamp studies. Further, not all missense variants were studied with patch clamp experiments.

In conclusion, we delineate the phenotypic spectrum of a CACNA1C-related neurological disorder variably associated with developmental delay, intellectual disability, autism, epilepsy, hypotonia, and ataxia. Significant cardiac abnormalities were absent in all but one of the individuals in our cohort at most recent follow-up. Although our sample size is limited, there appear to be phenotypic differences between individuals with truncating and non-truncating variants. While it is tempting to assume that these truncating variants result in a loss-of-function through haploinsufficiency, given the complexity of alternate splicing of this gene, this requires further validation. Further efforts to determine the precise molecular mechanism(s) for the neurological-predominant symptoms in some individuals with variants in the CACNA1C gene will provide additional insight into pathophysiology and potentially inform more targeted treatment.

\section{Acknowledgements:}

Research reported in this manuscript was supported by the NIH Common Fund, through the Office of Strategic Coordination/Office of the NIH Director under Award Number(s) [U01HG007709 (Baylor College of Medicine) and U01HG007672 (Duke University to Dr. Vandana Shashi)]. Additional funding for this project was under Award Number 1RO1HD090132-01A1 (Cornell University to Dr. Geoffrey Pitt). The content is solely the responsibility of the authors and does not necessarily represent the official views of the National Institutes of Health. 
Additional funding was provided by a Canadian Institutes of Health Research Grant (MOP-97988 to Harley T. Kurata), and a Rowland and Muriel Haryett Fellowship (University of Alberta, to Shawn M. Lamothe) and a fellowship from the Ministry of Education and Research of the Community of Madrid to Marta Pacio Míguez (B2017/BMD-3721), and microgrant from the Rare Disease Foundation (P.Y. Billie Au and Harley T. Kurata).

Sequencing and analysis was supported by the National Human Genome Research Institute grants UM1 HG008900 and R01 HG009141. K.A.D., B.C., and E.O. were supported the National Institute of Mental Health U01 MH119689.

\section{Ethics Declaration:}

Signed consent was obtained from parents/legal guardians for publication of photographs, in accordance with the institutional review boards/ethics committees at each individual institution. Clinical (de-identified and identifiable) and genetic data from all cases was analyzed with IRB approval under the UDN Study protocol (15-HG-0130) approved by the NIH IRB.

\section{Data Availability:}

The data for P12 (VCV000190670.1) and P13 (VCV00052282.1) have been submitted to ClinVar (https://www.ncbi.nlm.nih.gov/clinvar/) in accordance with the requirements of the Undiagnosed Diseases Network. The remaining de-identified data and variant information are available individually upon request. 
References:

1. I. Splawski, K.W. Timothy, L.M. Sharpe, N. Decher, P. Kumar, R. Bloise, C. Napolitano, P.J. Schwartz, R.M. Joseph, K. Condouris, et al. Ca(V)1.2 calcium channel dysfunction causes a multisystem disorder including arrhythmia and autism. Cell, 119(1) (2004), pp. 19-31.

2. Q. Zhang, J. Chen, Y. Qin, J. Wang, L. Zhou. Mutations in voltage-gated L-type calcium channel: implications in cardiac arrhythmia. Channels (Austin), 12(1) (2018), pp. 201-218.

3. S.M. Hosseini, R. Kim, S. Udupa, G. Costain, R. Jobling, E. Liston, S.M. Jamal, M. Szybowska, C.F. Morel, S. Bowdin, et al. Reappraisal of Reported Genes for Sudden Arrhythmic Death: Evidence-Based Evaluation of Gene Validity for Brugada Syndrome. Circulation, 138(12) (2018), pp. 1195-1205.

4. Green EK, Grozeva D, Jones I, Jones L, Kirov G, Caesar S et al. The bipolar disorder risk allele at CACNA1C also confers risk of recurrent major depression and of schizophrenia. Mol Psychiatry, 15 (2009), pp. 1-7.

5. X. Bozarth, J.N. Dines, Q. Cong, G.M. Mirzaa, K. Foss, J. L. Merritt II, J. Thies, H. C. Mefford, E. Novotny. Expanding clinical phenotype in CACNA1C related disorders: From neonatal onset severe epileptic encephalopathy to late-onset epilepsy. American Journal of Medical Genetics, 176(12)(2018), pp. 27332739.

6. I. Iossifov, B.J. O’Roak, S.J. Sanders, M. Romemus, N. Krumm, D. Levy, H.A. Stressman, K.T. Witherspoon, L. Vives, K.E. Patterson, et al. The contribution of de novo coding mutations to autism spectrum disorder. Nature, 515(7526) (2014), pp. 216-221.

7. Deciphering Developmental Disorders Study. Prevalence and architecture of de novo mututations in developmental disorders. Nature, 542(7642) (2017), pp. 433-438. 
8. C. Mio, N. Passon, F. Baldan, E. Bregant, E. Monaco, L. Mancini, E. Demori, G. Damante. CACNA1C haploinsufficiency accounts for the common features of interstitial 12p13.33 deletion carriers. Eur J. Med Genet, 63(4)(2020),pp. 103843.

9. J.L. Roberts, K. Hovanes, M. Dasouki, A.M. Manzardo, M.G. Butler. Chromosomal microarray analysis of consecutive individuals with autism spectrum disorders or learning disability presenting for genetic services. Gene, 535(1)(2014), pp. 70-78.

10. I. Quintela, J. Eirís, C. Gómez-Lado, L. Pérez-Gay, D. Dacruz, R. Cruz, M. Castro-Gago, L. Míguez, Á. Carracedo, F. Barros. Copy number variation analysis of patients with intellectual disability from North-West Spain. Gene, 626 (2017), pp. 189-199.

11. J. Chen, Y. Sun, X. Liu, J. Li. Identification of a novel mutation in the CACNA1C gene in a Chinese family with autosomal dominant cerebellar ataxia. BMC Neurol., 19(1)(2019), pp. 157.

12. N. Sobreira, F. Schiettecatte, D. Valle, A. Hamosh. GeneMatcher: A Matching Tool for Connecting Investigators with an Interest in the Same Gene. Hum Mutat. 36(10)(2015), pp. 928-930.

13. A.A. Philippakis, D.R. Azzariti, S. Beltran, A.J. Brookes, C.A. Brownstein, M. Brudno, H.G. Brunner, O.J. Buske, K. Carey, C. Doll, et al. The Matchmaker Exchange: A Platform for Rare Disease Gene Discovery. Hum Mutat. 36(10)(2015), pp.915-921.

14. J.A. Hennessey, N.J. Boczek, Y. Jiang, J.D. Miller, W. Patrick, R. Pfeiffer, B.S. Sutphin, D.J. Tester, H. Barajas-Martinez, M.J. Ackerman, et al. Voltage-dependent inactivation, increased CaV1.2 channel window current, and arrhythmogenesis. PLos One. 9(9)(2014), pp. e106982.

15. Y. Lin, S. McDonough, D. Lipscombe. Alternative splicing in the voltage-sensing region of $\mathbf{N}$-Type CaV2.2 channels modulates channel kinetics. J Neurophysiol. 92(5)(2004):2820-30. 
16. A.W. Wang, M.C. Yau, C.K. Wang, N. Sharmin, R.Y. Yang, S.A. Pless, H.T. Kurata. Four drug-sensitive subunits are required for maximal effect of a voltage sensor-targeted KCNQ opener. J Gen Physiol. 150(10)(2018),pp.1432-1443.

17. A. Auton, G. Abecasis, D. Altshuler, et al. A global reference for human genetic variation. Nature. 526 (2015), pp.68-74.

18. L. Wiel, C. Baakman, D. Gilissen, J.A. Veltman, G. Vriend, C. Gilissen. MetaDome: Pathogenicity analysis of genetic variants through aggregation of homologous human protein domains. Hum Mutat. 40(8)(2019), pp.1030-1038.

19. S. Gelfman, Q. Wang, K.M. McSweeney, Z. Ren, F. La Carpia, M. Halvorsen, K. Schoch, F. Ratzon, E.L. Heinzen, M.J. Boland, S. Petrovski, D.B. Goldstein. Annotating pathogenic non-coding variants in genic regions. Nat Commun. 8(1)(2017), pp. 236.

20. J. Striessnig, A. Pinggera, G. Kaur, G. Bock, P. Tuluc. L-type Ca2+ channels in heart and brain. Wiley Interdisciplinary Reviews: Membrane Transport and Signaling, 3(2)(2014), pp. 15-38.

21. D.G. Ehlinger, K.G. Commons. Cav1.2 L-type calcium channels regulate stress coping behavior via serotonin neurons. Neuropharmacology, 144 (2019), pp.282-290.

22. M.J. Betzenhauser, G.S. Pitt, C. Antzelevitch. Calcium Channel Mutations in Cardiac Arrhythmia Syndromes. Curr Mol Pharmacol, 8(2)(2015), pp.133-142.

23. K. Wmhoner, C. Friedrich, B. Stallmeyer, A.J. Coffey, A. Grace, S. Zumhagen, G. Seebohm, B. OrtizBonnin, S. Rinne, F.B. Sachse, et al. Gain-of-function mutations in the calcium channel CACNA1C 
(Cav1.2) cause non-syndromic long-QT but not Timothy syndrome. J. Mol. Cell Cardio, 80(2015), pp.186-195.

24. M.B. Clark, T. Wrzesinski, A. B. Garcia, N. A. L. Hall, J.E. Kleinman, T. Hyde, D.R. Weinberger, P.J. Harrison, W. Haerty, E.M. Tunbridge. Long-read sequencing reveals the complex splicing profile of the psychiatric risk gene CACNA1C in human brain. Molecular Psychiatry, 25(2020), pp.37-47.

25. D. Lipscombe, A. Andrade. Calcium Channel Cava1 Splice Isoforms - Tissue Specificty and Drug Action. Curr Mol Pharmacol, 8(1)(2015), pp. 22-31.

26. C. Sintas, O. Carreno, N. Fernandez-Castillo, R. Corominas, M. Vila-Pueyo, C. Toma, E. Cuenca-Leon, I. Barroeta, C. Roig, V. Volpini, et al. Mutation Spectrum in the CACNA1A Gene in 49 Patients with intolEpisodic Ataxia. Sci Rep. 31(7)(1)(2017), pp.2514

27. K.J. Karczewski, L.C. Francioli, G. Tiao, B.B. Cummings, J. Alfoldi, Q. Wang, R.L. Collins, K.M. Larichia, A. Ganna, D.P. Birnbaum, et al. The mutational constraint spectrum quantified from variation in 141,456 humans. Nature. 581 (2020), pp. 434-443.

28. F.H. Yu, M. Mantegazza, R.E. Westenbroek, C.A. Robbins, F. Kalume, K.A. Burton, W.J. Spain, G.S. McKnight. T. Scheuer, W.A. Catterall. Reduced sodium current in GABAergic interneurons in a mouse model of severe myoclonic epilepsy in infancy. Nature Neuroscience. 9(9)(2006),pp.1142-1149

29. A. Pinggeraa, G. Negroa, P. Tuluc a, M.J. Brownb, A. Lieb a, J. Striessni. Gating defects of diseasecausing de novo mutations in Cav1.3 Ca2+ channels. Channels. 12(1)(2018), pp.388-402.

30. U. Omasits, C.H. Ahrens, S. Müller, B. Wollscheid. Protter: interactive protein feature visualization and integration with experimental proteomic data. Bioinformatics. 15;30(6)(2014):884-886. doi: 10.1093/bioinformatics/btt607. 


\begin{tabular}{|c|c|c|c|c|c|c|c|c|c|c|c|c|c|c|}
\hline $\begin{array}{l}\text { Individual } \\
\text { Variants }\end{array}$ & $\begin{array}{l}\text { P1 } \\
\text { p.Phe166Leu } \\
\text { c.496T>C }\end{array}$ & $\begin{array}{l}\text { P2 } \\
\text { p.Lys177Arg } \\
\text { c.530A>G }\end{array}$ & $\begin{array}{l}\text { P3 } \\
\text { p.Arg324Trp } \\
\text { c.970C>T }\end{array}$ & $\begin{array}{l}\text { P4 } \\
\text { p.Val403Met } \\
\text { c.1207G>A }\end{array}$ & $\begin{array}{l}\text { P5 } \\
\text { p.Leu601Arg } \\
\text { c.1802T>G }\end{array}$ & $\begin{array}{l}\text { P6 } \\
\text { p.Met611Thr } \\
\text { c.1832T>C }\end{array}$ & $\begin{array}{l}\text { P7 } \\
\text { p.Leu614Arg } \\
\text { c.1841 T>G }\end{array}$ & $\begin{array}{l}\text { P8 } \\
\text { p.Leu614Pro } \\
\text { c.1841T>C }\end{array}$ & $\begin{array}{l}\text { P9 } \\
\text { p.Leu657Phe } \\
\text { c.1969C>T }\end{array}$ & $\begin{array}{l}\text { P10 } \\
\text { p.lle743del } \\
\text { c.2222- } \\
\text { 2229deleATC }\end{array}$ & $\begin{array}{l}\text { P11 } \\
\text { p.Val1187Ala } \\
\text { c.3560T>C }\end{array}$ & $\begin{array}{l}\text { P12 } \\
\text { p.Leu1408Val } \\
\text { c. } 4222 C>G\end{array}$ & $\begin{array}{l}\text { P13 } \\
\text { p.Val1411Leu } \\
\text { c. } 4231 \mathrm{G}>\mathrm{C}\end{array}$ & $\begin{array}{l}\text { P14 } \\
\text { p.Val1411Leu } \\
\text { c.4231G }>\text { T }\end{array}$ \\
\hline Inheritance & De novo & De novo & De novo & De novo & De novo & De novo & De novo & De novo & De novo & De novo & De novo & De novo & De novo & De novo \\
\hline $\begin{array}{l}\text { Age at most } \\
\text { recent exam }\end{array}$ & 23 years & 7.6 years & 9 years & 2.3 years & 4 years & 4 years & 2.5 years & 24 years & 15 years & 3.5 years & 1.5 years & 6.8 years & 7.8 years & 10 months \\
\hline Sex & Female & Female & Female & Female & Female & Male & Male & Male & Female & Male & Male & Female & Female & Male \\
\hline \multicolumn{15}{|l|}{ Development } \\
\hline Motor delay & + & + & + & + & + & + & + & + & + & + & + & + & + & + \\
\hline $\begin{array}{l}\text { Ambulatory (age } \\
\text { started } \\
\text { walking) }\end{array}$ & + (16 months) & + (15 months) & + (21 months) & - & $+(28$ months) & + (17 months) & $+(3$ years $)$ & - & $+(2$ years $)$ & - & - & - & - & - \\
\hline $\begin{array}{l}\text { Abnormal } \\
\text { muscle tone }\end{array}$ & Hypotonia & - & Hypotonia & Hypotonia & Hypotonia & Hypotonia & Hypotonia & Hypotonia & - & $\begin{array}{l}\text { Hypotonia, Leg } \\
\text { spasticity }\end{array}$ & Hypotonia & Hypotonia & Hypotonia & Hypotonia \\
\hline $\begin{array}{l}\text { Abnormal } \\
\text { balance/ } \\
\text { coordination }\end{array}$ & - & + & - & - & + & + & + & N/A & - & N/A & N/A & N/A & N/A & N/A \\
\hline Tremor & - & - & - & $\begin{array}{l}\text { Action tremor in } \\
\text { arms in first } 2 \\
\text { years, } \\
\text { subsequently } \\
\text { resolved }\end{array}$ & $\begin{array}{l}\text { Intention tremor } \\
\text { in arms, head } \\
\text { tremor }\end{array}$ & - & - & - & - & - & - & - & - & - \\
\hline Language delay & + & - & - & + & + & + & + & + & + & + & + & + & + & + \\
\hline Verbal ability & - & + & + & - & - & + & - & - & + & - & - & - & - & N/A \\
\hline $\begin{array}{l}\text { Clinical } \\
\text { diagnosis of } \\
\text { autism }\end{array}$ & - & - & - & - & - & - & - & + & - & - & - & - & - & - \\
\hline ADHD & - & - & - & - & - & - & - & - & - & - & - & - & - & - \\
\hline Cognition & $\begin{array}{l}\text { Severe } \\
\text { intellectual } \\
\text { disability }\end{array}$ & $\begin{array}{l}\text { Learning } \\
\text { disability }\end{array}$ & $\begin{array}{l}\text { Learning } \\
\text { disability, } \\
\text { dyslexia }\end{array}$ & $\begin{array}{l}\text { Mild-moderate } \\
\text { global } \\
\text { developmental } \\
\text { delay }\end{array}$ & $\begin{array}{l}\text { Mild intellectual } \\
\text { disability }\end{array}$ & $\begin{array}{l}\text { Mild global } \\
\text { developmental } \\
\text { delay }\end{array}$ & $\begin{array}{l}\text { Severe } \\
\text { developmental } \\
\text { delay }\end{array}$ & $\begin{array}{l}\text { Intellectual } \\
\text { disability, severity } \\
\text { unspecified }\end{array}$ & $\begin{array}{l}\text { Moderate-severe } \\
\text { intellectual } \\
\text { disability }\end{array}$ & $\begin{array}{l}\text { Severe global } \\
\text { developmental } \\
\text { delay }\end{array}$ & Unknown & $\begin{array}{l}\text { Severe } \\
\text { intellectual } \\
\text { disability }\end{array}$ & $\begin{array}{l}\text { Severe } \\
\text { intellectual } \\
\text { disability }\end{array}$ & $\begin{array}{l}\text { Severe global } \\
\text { developmental } \\
\text { delay }\end{array}$ \\
\hline \multicolumn{15}{|l|}{ Epilepsy } \\
\hline Seizures & + & + & + & - & - & + & + & + & + & - & + & + & + & + \\
\hline Age of onset & 6 years & 11 months & 8 years & $\mathrm{N} / \mathrm{A}$ & $N / A$ & 7 months & 10 months & 1 year & 6 years & N/A & 1 year & 6 months & 11 months & 2 months \\
\hline $\begin{array}{l}\text { Seizure types/ } \\
\text { epilepsy } \\
\text { syndrome }\end{array}$ & $\begin{array}{l}\text { Absence, } \\
\text { generalized } \\
\text { tonic-clonic }\end{array}$ & $\begin{array}{l}\text { Focal motor, } \\
\text { absence; seizures } \\
\text { fever-sensitive }\end{array}$ & Focal seizures & N/A & N/A & $\begin{array}{l}\text { West syndrome/ } \\
\text { infantile spasms }\end{array}$ & $\begin{array}{l}\text { Myoclonic } \\
\text { seizuresiz } \\
\text { generalized } \\
\text { tonic-clonic }\end{array}$ & $\begin{array}{l}\text { Generalized } \\
\text { epilepsy; seizures } \\
\text { are efever- } \\
\text { sensitive }\end{array}$ & $\begin{array}{l}\text { Behavioral arrest } \\
\text { spells }+1-\text { head } \\
\text { or limb jerking }\end{array}$ & N/A & $\begin{array}{l}\text { Seizures } \\
\text { provoked by } \\
\text { fever, diagnosed } \\
\text { as febrile seizures }\end{array}$ & $\begin{array}{l}\text { Myoclonic } \\
\text { seizures } \\
\rightarrow \text { multiple } \\
\text { generalized } \\
\text { seizure types/ } \\
\text { generalized } \\
\text { epilepsy } \\
\text { syndrome. }\end{array}$ & $\begin{array}{l}\text { West syndrome/ } \\
\text { infantile spasms } \\
\text { L Lennox- } \\
\text { Gastaut } \\
\text { syndrome }\end{array}$ & $\begin{array}{l}\text { Generalized } \\
\text { epilepsy }\end{array}$ \\
\hline \multicolumn{15}{|c|}{ Cardiac abnormalities } \\
\hline $\begin{array}{l}\text { Abnormal ECG/ } \\
\text { Holter }\end{array}$ & N/A & - & - & - & N/A & - & - & - & - & - & N/A & $\begin{array}{l}\text { Possible } \\
\text { ventricular } \\
\text { conduction delay }\end{array}$ & Prolonged QT & $\begin{array}{l}\text { - (Borderline } \\
\text { QTc } 450 \mathrm{msec})\end{array}$ \\
\hline Abnormal ECHO & N/A & $N / A$ & - & $\begin{array}{l}\text { Small interatrial } \\
\text { communication } \\
\text { in the upper part } \\
\text { of the atrial } \\
\text { septum with left- } \\
\text { right shunt }\end{array}$ & $N / A$ & - & $N / A$ & - & $N / A$ & - & - & $\begin{array}{l}\text { Trace Al, trivial } \\
\text { TR, trace PR }\end{array}$ & - & $\begin{array}{l}\text { - (Previously } \\
\text { known PDAA/PFO } \\
\text { have since } \\
\text { closed) }\end{array}$ \\
\hline $\begin{array}{l}\text { Orthopedic } \\
\text { abnormalities }\end{array}$ & Pes planovalgus & $\begin{array}{l}\text { Congenital hip } \\
\text { dysplasia }\end{array}$ & Hypermobility & $\begin{array}{l}\text { Left hip } \\
\text { dislocation and } \\
\text { right hip } \\
\text { subluxation, joint } \\
\text { hypermobility }\end{array}$ & $\begin{array}{l}\text { Pes planovalgus, } \\
\text { joint } \\
\text { hypermobility, } \\
\text { toe-walking }\end{array}$ & - & $\begin{array}{l}\text { Bilateral clubfoot, } \\
\text { and adducted } \\
\text { thumbs }\end{array}$ & Kyphosis & $\begin{array}{l}\text { Small appearing } \\
\text { feet, tapered } \\
\text { fingers }\end{array}$ & $\begin{array}{l}\text { Bilateral clubfoot, } \\
\text { prominent heels } \\
\text { in small } \\
\text { appearing feet, } \\
\text { adducted thumb, } \\
\text { and } \\
\text { camptodactyly of } \\
\text { fingers, tapering } \\
\text { fingers }\end{array}$ & $\begin{array}{l}\text { Cutaneous 2-3 } \\
\text { toe syndactyly } \\
\text { and mild } 3-4 \\
\text { finger syndactyly, } \\
\text { congenital } \\
\text { torticollis }\end{array}$ & $\begin{array}{l}\text { Kyphoscoliosis, } \\
\text { coxa valga }\end{array}$ & - & $\begin{array}{l}\text { Bilateral } \\
\text { congenital hip } \\
\text { dysplasia, toe 2-3 } \\
\text { syndactryly } \\
\text { bilateraly, } \\
\text { bilateral } \\
\text { adducted } \\
\text { thumbs }\end{array}$ \\
\hline $\begin{array}{l}\text { Ophthalmological } \\
\text { abnormalities }\end{array}$ & Unknown & - & $\begin{array}{l}\text { Strabismus, } \\
\text { hyperopia }\end{array}$ & $\begin{array}{l}\text { Strabismus } \\
\text { (nonparalytic) }\end{array}$ & Myopia & - & Strabismus & $\begin{array}{l}\begin{array}{l}\text { Hyperopia, } \\
\text { astigmatism }\end{array} \\
\text { a }\end{array}$ & - & Severe hyperopia & $\begin{array}{l}\text { Hyperopia, } \\
\text { astigmatism, } \\
\text { esotropia }\end{array}$ & Strabismus & $\begin{array}{l}\text { Cortical visual } \\
\text { impairment }\end{array}$ & - \\
\hline
\end{tabular}




\begin{tabular}{|c|c|c|c|c|c|c|c|c|c|c|c|c|c|c|}
\hline $\begin{array}{l}\text { Individual } \\
\text { Variants }\end{array}$ & $\begin{array}{l}\text { P1 } \\
\text { p.Phe166Leu } \\
\text { c.496T>C }\end{array}$ & $\begin{array}{l}\text { P2 } \\
\text { p.Lys177Arg } \\
\text { c.530A>G }\end{array}$ & $\begin{array}{l}\text { P3 } \\
\text { p.Arg324Trp } \\
\text { c.970C>T }\end{array}$ & $\begin{array}{l}\text { P4 } \\
\text { p.Val403Met } \\
\text { c.1207G>A }\end{array}$ & $\begin{array}{l}\text { P5 } \\
\text { p.Leu601Arg } \\
\text { c.1802T>G }\end{array}$ & $\begin{array}{l}\text { P6 } \\
\text { p.Met611Thr } \\
\text { c.1832T>C }\end{array}$ & $\begin{array}{l}\text { P7 } \\
\text { p.Leu614Arg } \\
\text { c.1841 T>G }\end{array}$ & $\begin{array}{l}\text { P8 } \\
\text { p.Leu614Pro } \\
\text { c.1841T>C }\end{array}$ & $\begin{array}{l}\text { P9 } \\
\text { p.Leu657Phe } \\
\text { c.1969C>T }\end{array}$ & $\begin{array}{l}\text { P10 } \\
\text { p.lle743del } \\
\text { c.22227 } \\
\text { 22229deleATC }\end{array}$ & $\begin{array}{l}\text { P11 } \\
\text { p.Val1187Ala } \\
\text { c.3560T>C }\end{array}$ & $\begin{array}{l}\text { P12 } \\
\text { p.Leu1408Val } \\
\text { c.4222C }>G\end{array}$ & $\begin{array}{l}\text { P13 } \\
\text { p.Val1411Leu } \\
\text { c.4231G>C }\end{array}$ & $\begin{array}{l}\text { P14 } \\
\text { p.Val1411Leu } \\
\text { c.4231G }>T\end{array}$ \\
\hline $\begin{array}{l}\text { Dysmorphic } \\
\text { features }\end{array}$ & + & - & - & - & + & - & - & + & + & + & - & - & - & + \\
\hline
\end{tabular}




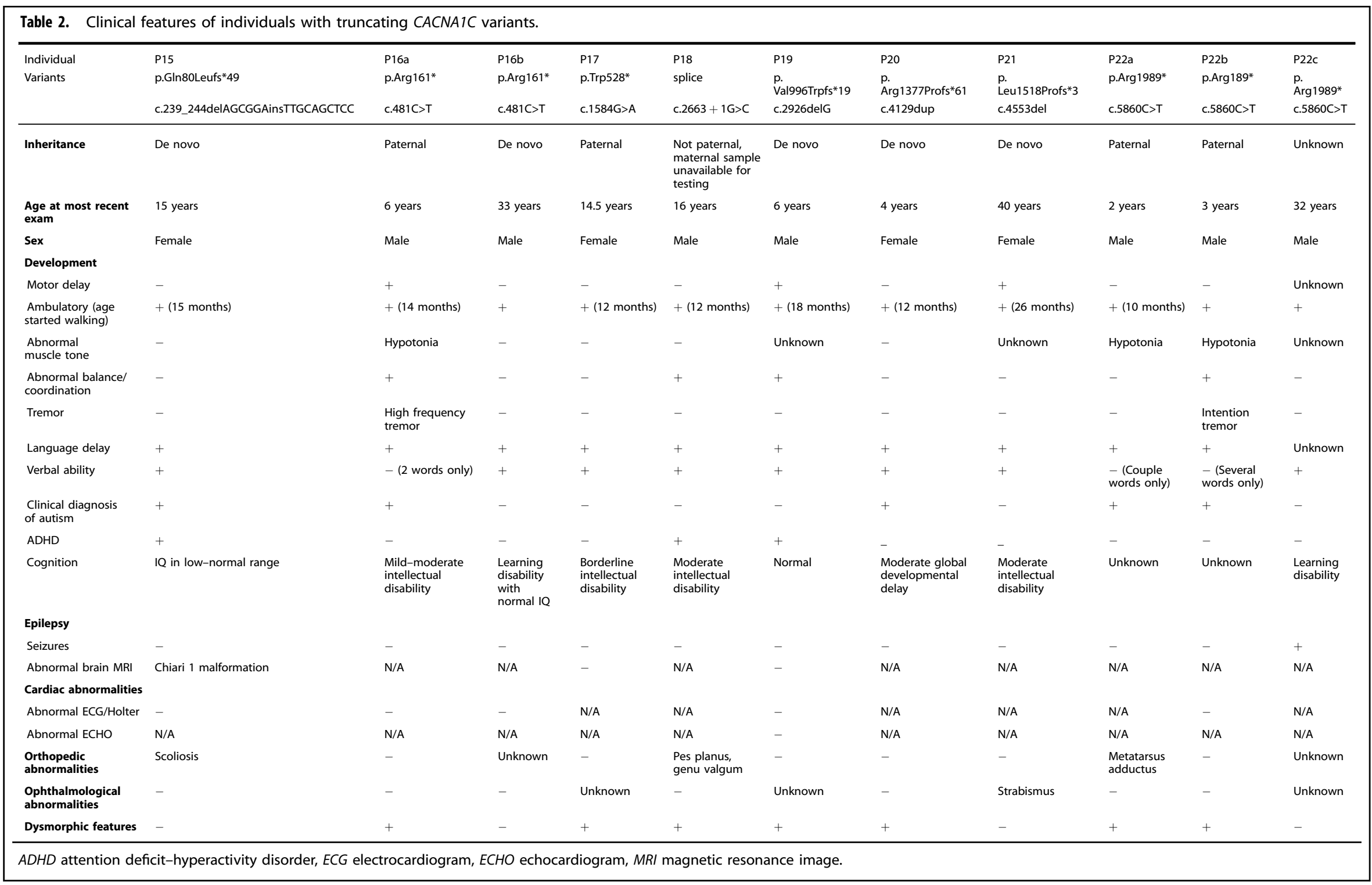


FIGURE LEGEND:

Figure 1a:

Spectrum of dysmorphology seen in individuals with CACNA1C non-truncating variants. A) Individual P1 at age 23 years. Note pes planovalgus B) Individual P5 at age 4 years C) Individual P10. Note clubfoot in infancy, and small appearing feet with prominent heels, adducted thumb, and camptodactyly later in childhood. D) Individual P12 at age 6 years of age. Note strabismus and kyphoscoliosis. E) Individual 13 at age 6 years old.

Figure 1b:

Spectrum of dysmorphology seen in individuals with CACNA1C truncating variants: A) Individual 15 at 15 years old. B) Individual 16a at 6 years old. Note large ears. C) Individual P18. Note mildly broad thumbs, hypoplastic $5^{\text {th }}$ fingernails, broad halluces, and hypoplastic fifth toes. D) Individual P19 at age.

\section{Figure 2:}

Characterization of Cav1.2 missense variants (L614P, L657F, L1408V, and L614R): A), Representative whole-cell $\mathrm{Ca}^{2+}$ current traces after heterologous expression of Cav $\beta 3$, Cav $\alpha 2 \delta 1$ and either Cav1.2 WT or Cav1.2 variants L614P, L657F, and L1408V in HEK293 cells. Solutions and voltage protocols used to elicit $\mathrm{Ca}^{2+}$ currents are described in the methods section. B), Averaged current-voltage (I-V) curves from wholecell patch clamp measurements of HEK293 cells expressing Cavß3, Cav $\alpha 2 \delta 1$ and either Cav1.2 WT ( $\mathrm{n}=14)$ or Cav1.2 variants L614P ( $n=11)$, L657F $(n=8)$, and L1408V $(n=10) . C$ ), Current density $(p A / p F)$ analysis of the peak current of Cav1.2 WT ( $n=14)$ or Cav1.2 variants L614P $(n=11)$, L657F $(n=8)$, and L1408V $(n=10)$ from cell recordings in A and B. Individual cells (open circles) are overlapped with the average current density $(\mathrm{pA} / \mathrm{pF})$, depicted as bars in the graph. Statistical analyses were carried out with a one-way ANOVA test. * $p<0.05$ vs. Cav1.2 WT. D), Representative Western blot of whole-cell lysate from HEK293 cells 
heterologously expressed with Cavß3, Cav $\alpha 2 \delta 1$ and either Cav1.2 WT or Cav1.2 variants L614P, L657F, and L1408V. Actin was used as loading control. Antibodies used for immunoblotting of proteins are described in the methods section. E), Densitometry analysis of Cav1.2 WT ( $n=9$ ) or Cav1.2 variants (L614P $(n=9)$, L657F $(n=9)$, and L1408V $(n=9))$ protein band intensities relative to the respective actin band intensities. Individual cells (open circles) are overlapped with the average relative Cav1.2 band intensities (240 kDa), depicted as bars in the graph. Statistical analyses were carried out with a one-way ANOVA test. ${ }^{*} p<0.05$ vs. Cav1.2 WT. F) Averaged current-voltage (I-V) curves from whole-cell patch clamp measurements of HEK293 cells expressing CACNB2, CACNA2D, EGFP and either Cav1.2 WT ( $\mathrm{n}=14$ ) or Cav1.2 variant L614R ( $\mathrm{n}=9)$. Differences in current density do not meet statistical significance.

\section{Figure 3:}

Location of CACNA1C variants in 25 individuals. Blue dots indicate missense variants or in-frame deletion, and red dots indicate truncating variants. Protein alterations are spread throughout the protein, although there is a clustering of missense variants in one of the linker segments of domain II (exon 13) and domain IV (exon 35), suggesting the potential significance of these regions of the protein in the function of CACNA1C in the central nervous system. Figure was created using open-source tool, Protter $^{30}$. 
a
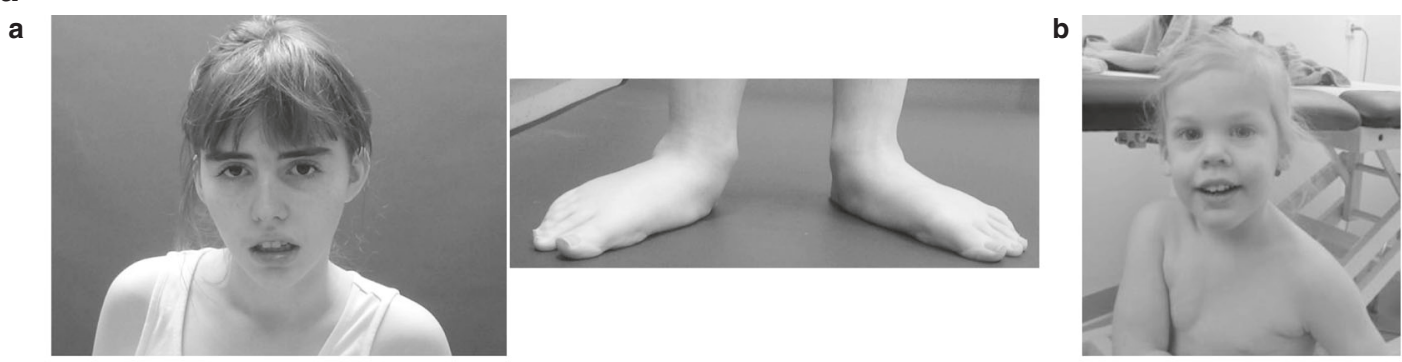

C

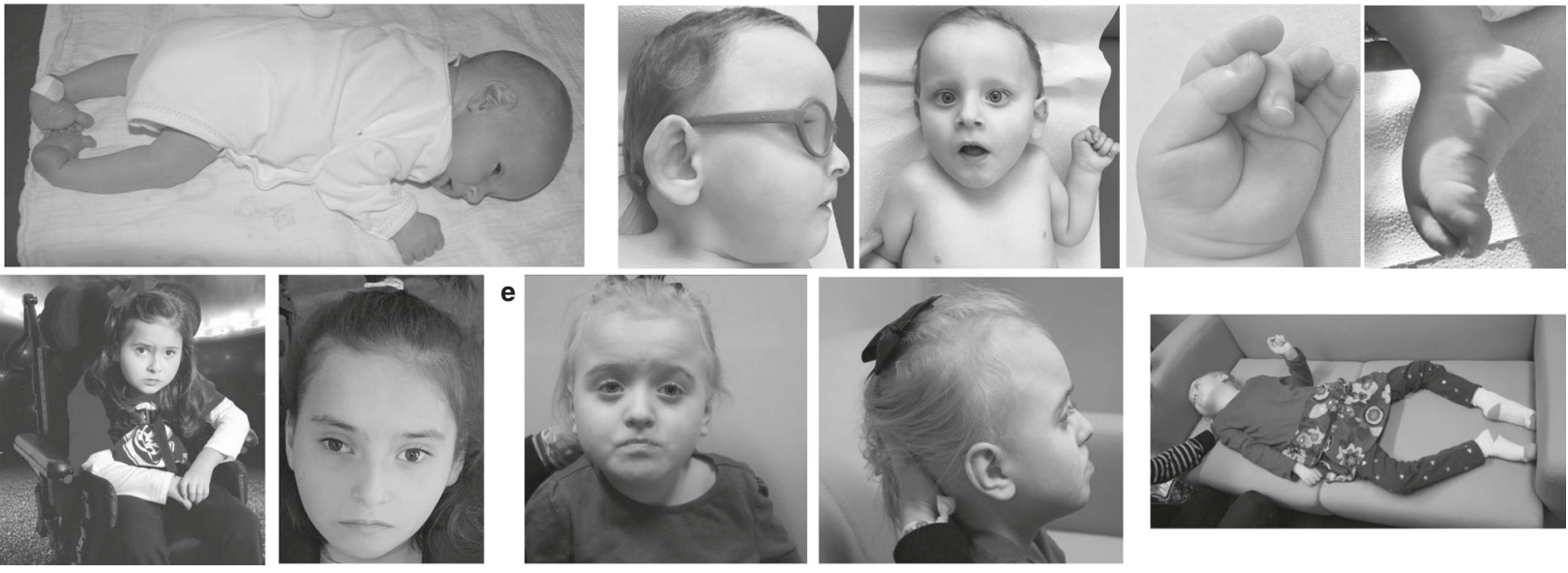

b
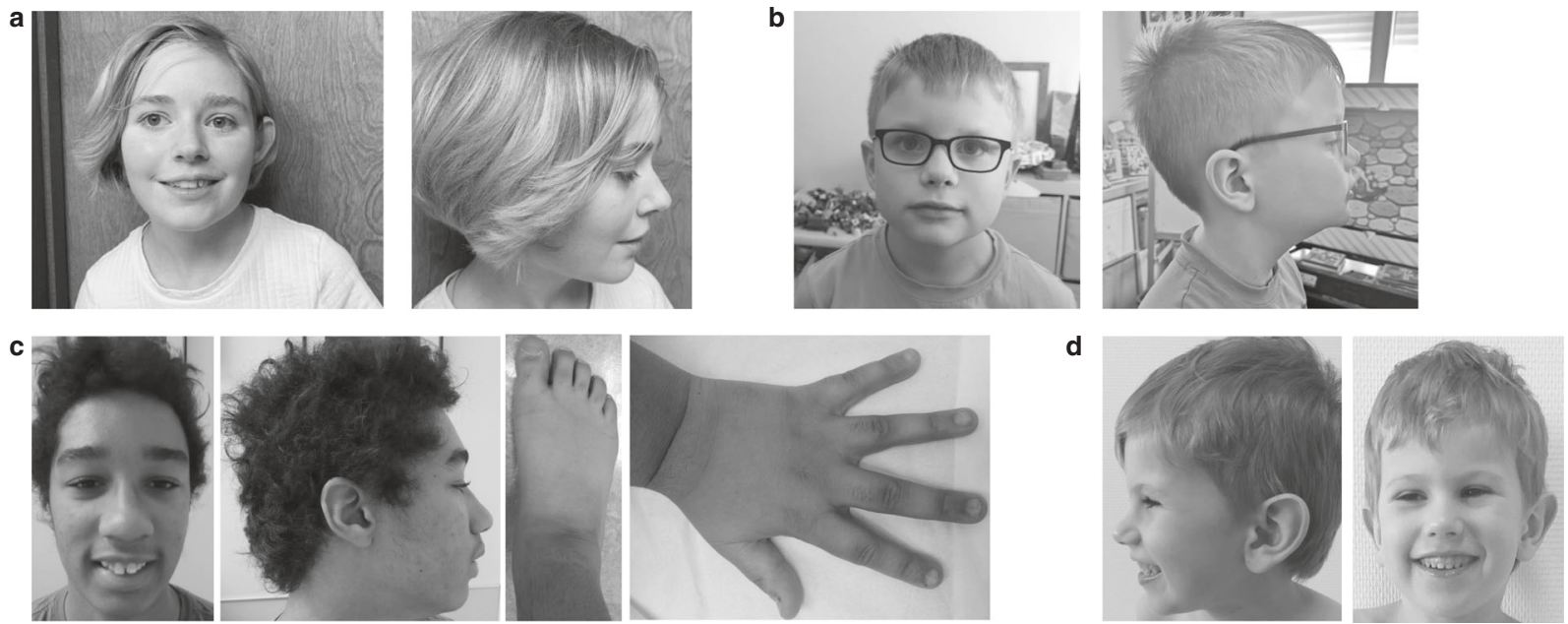

Fig. 1 Dysmorphology seen in individuals with CACNA1C variants. (a) Spectrum of dysmorphology seen in individuals with CACNA1C nontruncating variants. (a) Individual P1 at age 23 years. Note pes planovalgus. (b) Individual P5 at age 4 years. (c) Individual P10. Note clubfoot in infancy, and small appearing feet with prominent heels, adducted thumb, and camptodactyly later in childhood. (d) Individual P12 at age 6 years of age. Note strabismus and kyphoscoliosis. (e) Individual 13 at age 6 years old. (b) Spectrum of dysmorphology seen in individuals with CACNA1C truncating variants. (a) Individual 15 at 15 years old. (b) Individual 16a at 6 years old. Note large ears. (c) Individual P18. Note mildly broad thumbs, hypoplastic 5th fingernails, broad halluces, and hypoplastic fifth toes. (d) Individual P19 at age. 
a
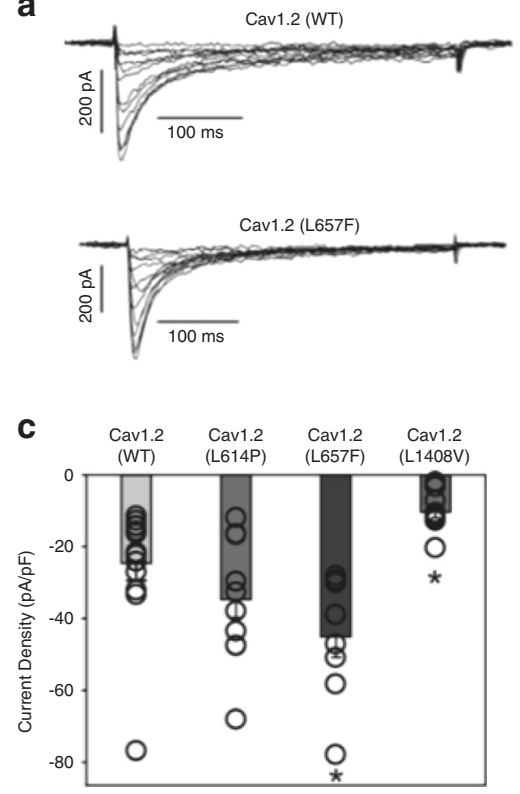

f

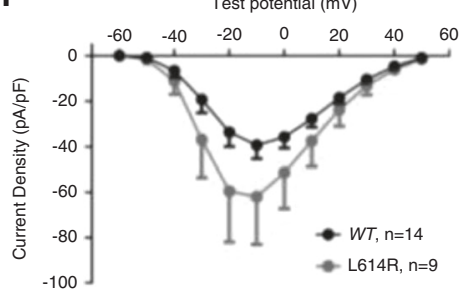

Cav1.2 (L614P)

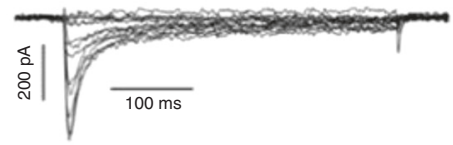

Cav1.2 (L1408V)

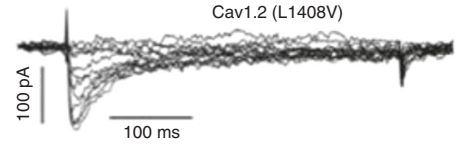

d

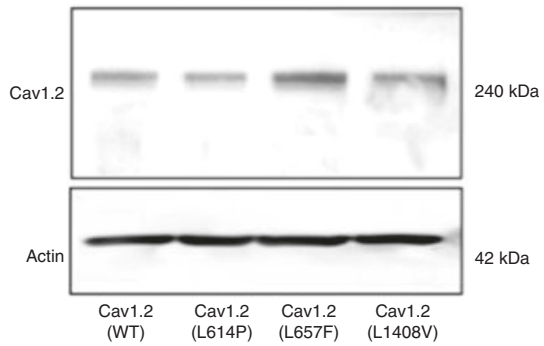

b

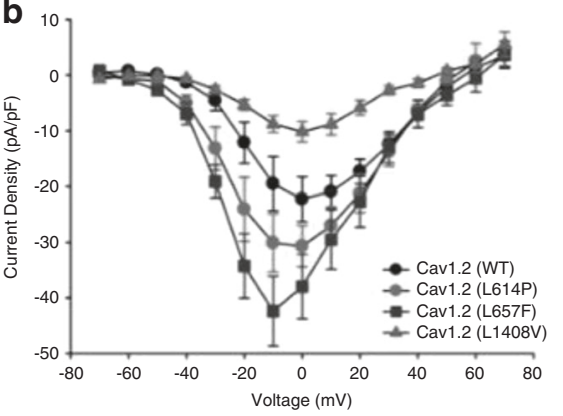

e

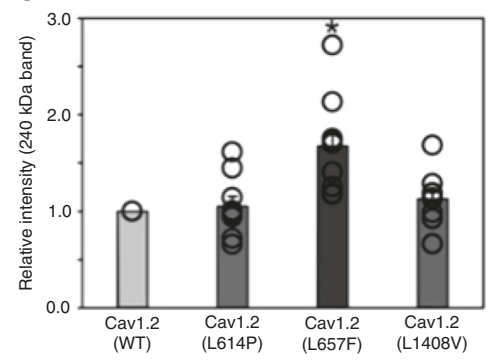

Fig. 2 Characterization of Cav1.2 missense variants (L614P, L657F, L1408V, and L614R). (a) Representative whole-cell Ca ${ }^{2+}$ current traces after heterologous expression of Cav 33 , Cav $\alpha 281$, and either Cav1.2 wild-type (WT) or Cav1.2 variants L614P, L657F, and L1408V in HEK293 cells. Solutions and voltage protocols used to elicit $\mathrm{Ca}^{2+}$ currents are described in the methods section. (b) Averaged current-voltage (I-V) curves from whole-cell patch clamp measurements of HEK293 cells expressing Cav $\beta 3$, Cav $\alpha 2 \delta 1$ and either Cav1.2 WT ( $n=14)$ or Cav1.2 variants L614P $(n=11)$, L657F $(n=8)$, and L1408V $(n=10)$. (c) Current density $(\mathrm{pA} / \mathrm{pF})$ analysis of the peak current of Cav1.2 WT ( $n=14)$ or Cav1.2 variants L614P $(n=11)$, L657F $(n=8)$, and L1408V $(n=10)$ from cell recordings in (a) and (b). Individual cells (open circles) are overlapped with the average current density $(\mathrm{pA} / \mathrm{pF})$, depicted as bars in the graph. Statistical analyses were carried out with a one-way analysis of variance (ANOVA) test. ${ }^{*} p<0.05$ vs. Cav1.2 WT. (d) Representative western blot of whole-cell lysate from HEK293 cells heterologously expressed with Cav $\beta 3$, Cav $\alpha 2 \delta 1$ and either Cav1.2 WT or Cav1.2 variants L614P, L657F, and L1408V. Actin was used as loading control. Antibodies used for immunoblotting of proteins are described in the methods section. (e) Densitometry analysis of Cav1.2 WT ( $n=9$ ) or Cav1.2 variants (L614P [ $n=9$ ], L657F $[n=9]$, and L1408V $[n=9]$ ) protein band intensities relative to the respective actin band intensities. Individual cells (open circles) are overlapped with the average relative Cav1.2 band intensities (240 kDa), depicted as bars in the graph. Statistical analyses were carried out with a one-way ANOVA test. ${ }^{*} p<0.05$ vs. Cav1.2 WT. (f) Averaged current-voltage (I-V) curves from wholecell patch clamp measurements of HEK293 cells expressing CACNB2, CACNA2D, EGFP and either Cav1.2 WT $(n=14)$ or Cav1.2 variant L614R $(n$ $=9$ ). Differences in current density do not meet statistical significance. 


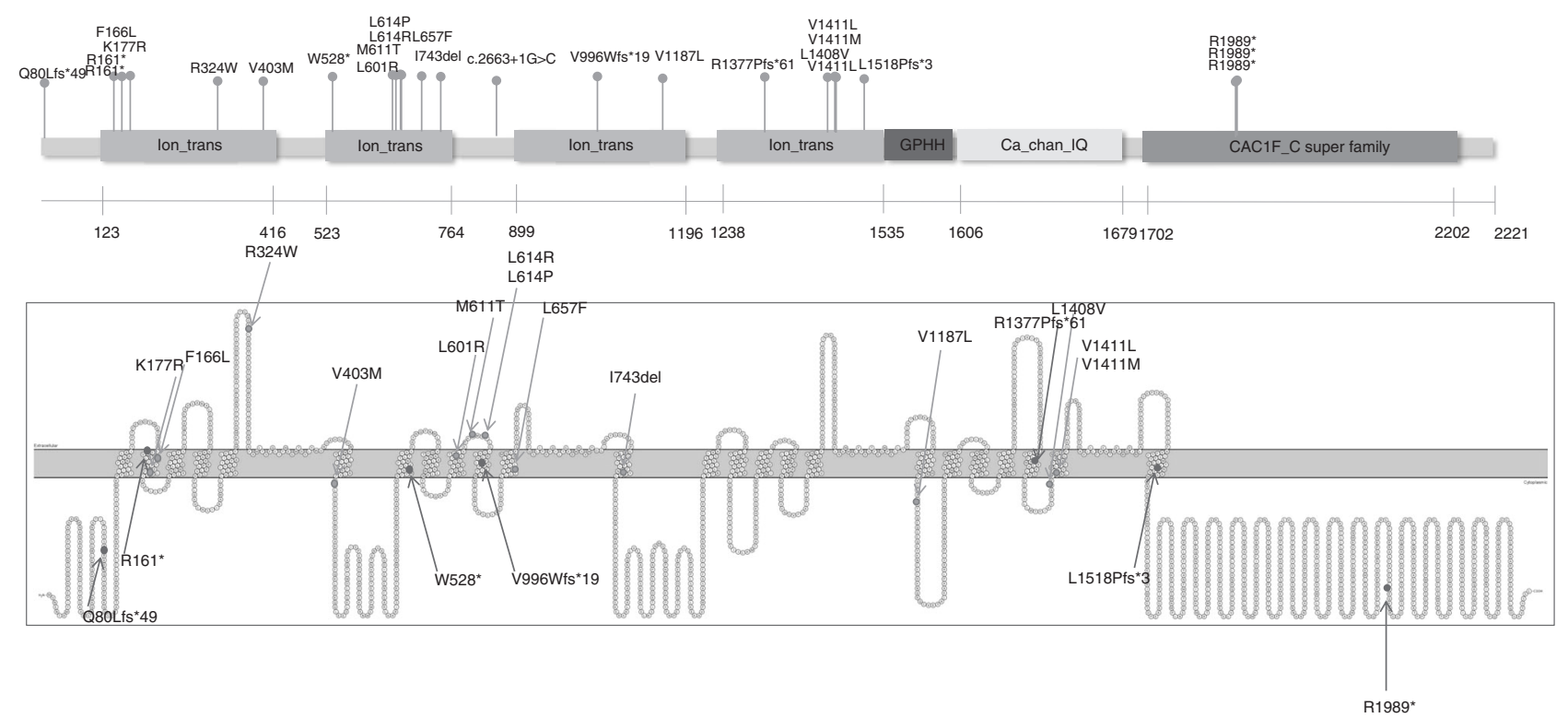

Fig. 3 Location of CACNA1C variants in 25 individuals. Blue dots indicate missense variants or in-frame deletion, and red dots indicate truncating variants. Protein alterations are spread throughout the protein, although there is a clustering of missense variants in one of the linker segments of domain II (exon 13) and domain IV (exon 35), suggesting the potential significance of these regions of the protein in the function of CACNA1C in the central nervous system. Figure was created using open-source tool, Protter [30]. 